\title{
X-Linked Adrenal Hypoplasia Congenita: A Mutation in DAX1 Expands the Phenotypic Spectrum in Males and Females*
}

\author{
STEPHANIE B. SEMINARA, JOHN C. ACHERMANN, MYRON GENEL, \\ J. LARRY JAMESON, AND WILLIAM F. CROWLEY, JR. \\ Reproductive Endocrine Unit, Massachusetts General Hospital (S.B.S., W.F.C.), Boston, Massachusetts \\ 02114; the Division of Endocrinology, Metabolism, and Molecular Medicine, Northwestern University \\ Medical School (J.C.A., J.L.J.), Chicago, Illinois 60611; and the Section of Pediatric Endocrinology, \\ Yale University School of Medicine (M.G.), New Haven, Connecticut 06520
}

\begin{abstract}
X-linked adrenal hypoplasia congenita (AHC) is a disorder associated with primary adrenal insufficiency and hypogonadotropic hypogonadism (HH). The gene responsible for X-linked AHC, DAX1, encodes a member of the nuclear hormone receptor superfamily. We studied an extended kindred with $\mathrm{AHC}$ and $\mathrm{HH}$ in which two males (the proband and his nephew) were affected with a nucleotide deletion (501delA). The proband's mother, sister, and niece were heterozygous for this frameshift mutation. At age $27 \mathrm{yr}$, after $7 \mathrm{yr}$ of low dose hCG therapy, the proband underwent a testicular biopsy revealing rare spermatogonia and Leydig cell hyperplasia. Despite steadily progressive doses of hCG and Pergonal administered over a 3-yr period, the proband remained azoospermic. The proband's mother, sister (obligate carrier), and niece all had a history of delayed puberty, with menarche occurring at ages 17-18 yr.

Baseline patterns of pulsatile gonadotropin secretion and gonadotropin responsiveness to exogenous pulsatile GnRH were examined
\end{abstract}

in the affected males. LH, FSH, and free $\alpha$-subunit were determined during $12.5-24 \mathrm{~h}$ of frequent blood sampling (every $10 \mathrm{~min}$ ). Both patients then received pulsatile $\mathrm{GnRH}(25 \mathrm{ng} / \mathrm{kg})$ sc every $2 \mathrm{~h}$ for $6-7$ days. Gonadotropin responses to a single $\mathrm{GnRH}$ pulse iv were monitored daily to assess the pituitary responsiveness to exogenous GnRH. In the proband, FSH and LH levels demonstrated a subtle, but significant, response to GnRH over the week of pulsatile GnRH therapy. Free $\alpha$-subunit levels demonstrated an erratic pattern of secretion at baseline and no significant response to pulsatile $\mathrm{GnRH}$.

We conclude that 1) affected males with $\mathrm{AHC} / \mathrm{HH}$ may have an intrinsic defect in spermatogenesis that is not responsive to gonadotropin therapy; 2) female carriers of DAX1 mutations may express the phenotype of delayed puberty; and 3) although affected individuals display minimal responses to pulsatile $\mathrm{GnRH}$, as observed in other AHC kindreds, subtle differences in gonadotropin patterns may nevertheless exist between affected individuals within a kindred. (J Clin Endocrinol Metab 84: 4501-4509, 1999)
A DRENAL hypoplasia congenita is a rare developmental disorder of the adrenal gland. In the X-linked cytomegalic form, the adrenal glands lack the permanent adult zone of the adrenal cortex (1). Affected boys typically present with adrenal insufficiency in early infancy or childhood and hypogonadotropic hypogonadism $(\mathrm{HH})$ at the time of puberty (2). The gene responsible for adrenal hypoplasia congenita (AHC) is DAX1 (dosage-sensitive, sex reversal, adrenal hypoplasia congenita, critical region on the $\mathrm{X}$-chromosome, gene 1), which encodes for a protein that is a member of the orphan nuclear hormone receptor superfamily (3, 4). Although the carboxyl-terminus of DAX-1 (putative ligand-binding domain) displays sequence homology with several other transcription factors, the amino-terminus of DAX-1 has a novel amino acid tandem repeat structure that lacks the zinc finger motif typically present in the DNA-

Received April 13, 1999. Revision received July 7, 1999. Accepted August 9, 1999.

Address all correspondence and requests for reprints to: Stephanie B. Seminara, M.D., Reproductive Endocrine Unit, Bartlett Hall Extension 505, Massachusetts General Hospital, Fruit Street, Boston, Massachusetts 02114. E-mail: seminara.stephanie@mgh.harvard.edu.

* This work was supported by the National Center for Infertility Research (U54-HD-29164) and the Reproductive Endocrine Sciences Center (P30-HD-28138) at Massachusetts General Hospital and Harvard Medical School. binding domain of other nuclear hormone receptors (4). A range of frameshift and nonsense mutations has been reported throughout DAX1 in patients with $\mathrm{AHC}$ and $\mathrm{HH}$. These mutations cause truncation of the functionally important carboxyl-terminal region of the protein (5). Missense mutations in DAX1 are relatively rare and, to date, are also localized within the putative ligand-binding domain alone (5). Additional lines of evidence suggest that such disruptions of the C-terminus impair DAX-1 interaction with steroidogenic factor-1 (6).

Long term data on gonadal function in patients with $\mathrm{AHC} / \mathrm{HH}$ is lacking. No cases of true fertility have yet been reported in men with this condition. It is unclear whether fertility can be induced in these patients by using exogenous gonadotropins, as Dax-1 is also expressed in Sertoli cells, and the recently reported Ahch (Dax1) knockout mouse demonstrates markedly disordered spermatogenesis (7). In addition, little information has been available regarding the phenotypic status of female carriers of DAX1 gene mutations. However, recently, a female with isolated $\mathrm{HH}$ was found to be homozygous for a DAX1 nonsense mutation, demonstrating a unique molecular etiology for this disorder (8).

Much of the early clinical data on AHC patients examined whether the hypogonadism of these individuals was due to defects at the hypothalamus or pituitary. Attempts to stimulate gonadotropin secretion were conducted using pulsatile 
GnRH. Although these cases predated the discovery of $D A X 1$ (and, by extension, do not represent confirmed DAX1 mutations), investigators were unable to resolve whether the hypogonadism of AHC was of hypothalamic or pituitary origin (9-13). However, by 1) conducting frequent (every 10-20 min) blood sampling for LH, FSH, and free $\alpha$-subunit (FAS) to examine the baseline pulsatile activity of the hypothalamic-pituitary-gonadal (HPG) axis and 2) administering exogenous pulsatile GnRH at physiological doses to two patients with different DAX-1 mutations, we have been able to demonstrate that DAX-1 can impair gonadotropin production by acting at both hypothalamic and pituitary levels (14).

This study presents an extended kindred with $\mathrm{AHC} / \mathrm{HH}$. The proband of this family failed to develop spermatogenesis despite 3 yr of exogenous gonadotropin therapy, suggesting the presence of an independent gonadal defect in $\mathrm{AHC} / \mathrm{HH}$. In addition, this family demonstrates the novel finding that delayed puberty can be a manifestation of DAX1 mutations in females. The results of detailed hypothalamic-pituitarygonadal investigations in two members of this kindred are also presented.

\section{Subjects and Methods}

\section{Case presentations}

The proband, III-9 (Fig. 1), was the product of a full-term, normal, spontaneous delivery. He presented at 11 days of life with poor intake, drowsiness, and weight loss and presented again at 4 weeks with malnutrition and dehydration. At that time, examination revealed mottled skin with poor turgor, but the abdomen, genitalia, and extremities were normal. Electrolyte determinations consistently showed low sodium and chloride and elevated potassium levels. Serum cortisol levels were subnormal, with only a 2- to 3 -fold increase after ACTH administration. The patient remained hospitalized for the next 2.5 months and received cortisone treatment. He was discharged with a diagnosis of transient hypoadrenalism of infancy. Although he did not require any steroid supplementation during childhood, III-9 recollects a childhood preference for salty foods. He presented at age $12 \mathrm{yr}$ with anorexia, weight loss, poor growth, and hyponatremia $(\mathrm{Na}, 118 \mathrm{mEq} / \mathrm{L})$. Physical examination was notable for hyperpigmentation, and he was begun on hydrocortisone and fludrocortisone treatment.

In his teen years, III-9 presented with delayed puberty. A presump- tive diagnosis of $\mathrm{HH}$ was made, and hCG (1000 U, im, every 5 days) was initiated at age $19 \mathrm{yr}$. An excellent response to hCG was evident, with respect to both virilization and sexual function. He was $5 \mathrm{ft} 4 \mathrm{in}$. when he graduated high school and $6 \mathrm{ft} 4 \mathrm{in}$. when he graduated college. At age $27 \mathrm{yr}$, a testicular biopsy was performed, which revealed Sertoli cell only syndrome with rare spermatogonia and no apparent spermatogenesis (Fig. 2).

After the biopsy, in an attempt to achieve fertility, III-9 initiated combination therapy with hCG and Pergonal ( $75 \mathrm{U}$, im, three times per week). Initially, physical examination revealed a testicular size of $5 \mathrm{cc}$ bilaterally. After 3 yr of therapy (dose escalations to 2000 U hCG and 150 U Pergonal, im, three times per week), testicular size increased to $10 \mathrm{cc}$ bilaterally, but semen analyses failed to show any sperm. The patient discontinued gonadotropins, declined pulsatile $\mathrm{GnRH}$, and initiated testosterone therapy.

The patient had five siblings, three of whom died prematurely. A 14yr-old sister had homocystinuria (III-8), a 2.5-yr-old sister died of nephritis (III-3), and a boy born 2 months prematurely died at 2.5 days of age (III-2). The proband's brother underwent normal puberty and development. The proband's father had a history of thyrotoxicosis. His mother (II-4) had a history of delayed puberty, with menarche at age $17 \mathrm{yr}$.

The patient III-9's surviving sister (III-4), similar to her mother, also underwent a delayed menarche at age 17-18 yr. However, after completion of puberty, she maintained regular menstrual cycles and conceived two children. In 1981, she had a healthy daughter (IV-1), who had normal growth and development, but did not undergo menarche until age 17 yr. Although the history is vague, both III-4 and IV-1 underwent pubarche and thelarche in their early teens. All three women in this lineage had no history of eating disorder, marked weight loss, major life stressors, or competitive athletics, with the exception of IV-1, who ran on her high school track team.

In 1983, III-4 bore a son (IV-2) who was an 8-lb 5-oz product of an uncomplicated full-term pregnancy. He presented at 4 weeks of age with irritability, dehydration, hyponatremia, and hyperkalemia. Physical examination revealed a slightly thin but well developed male infant with normally descended testes. During hospital admission, IV-2 was treated with hydrocortisone and iv sodium chloride; fludrocortisone and deoxycorticosterone acetate were added to his regimen. Work-up revealed an elevated serum renin, low serum aldosterone, and normal serum testosterone $(209 \mathrm{ng} / \mathrm{dL}), \mathrm{LH}(6 \mathrm{mIU} / \mathrm{mL}), \mathrm{FSH}(2 \mathrm{mIU} / \mathrm{mL})$, and $17 \alpha$ hydroxyprogesterone (352 ng/dL). Patient IV-2 was switched to dexamethasone and readmitted at 7.5 weeks for confirmation of his diagnosis with ACTH stimulation testing. A 3-day ACTH stimulation test yielded no cortisol elevation, and he was restarted on hydrocortisone and fludrocortisone, with intermittent injections of deoxycorticosterone.

Patient IV-2 remained well below the fifth percentile on his growth curve throughout infancy and childhood, with a height age equivalent to $4 \mathrm{yr}$ at age $6 \mathrm{yr}$. He had two episodes of adrenal insufficiency,

FIG. 1. Family pedigree.

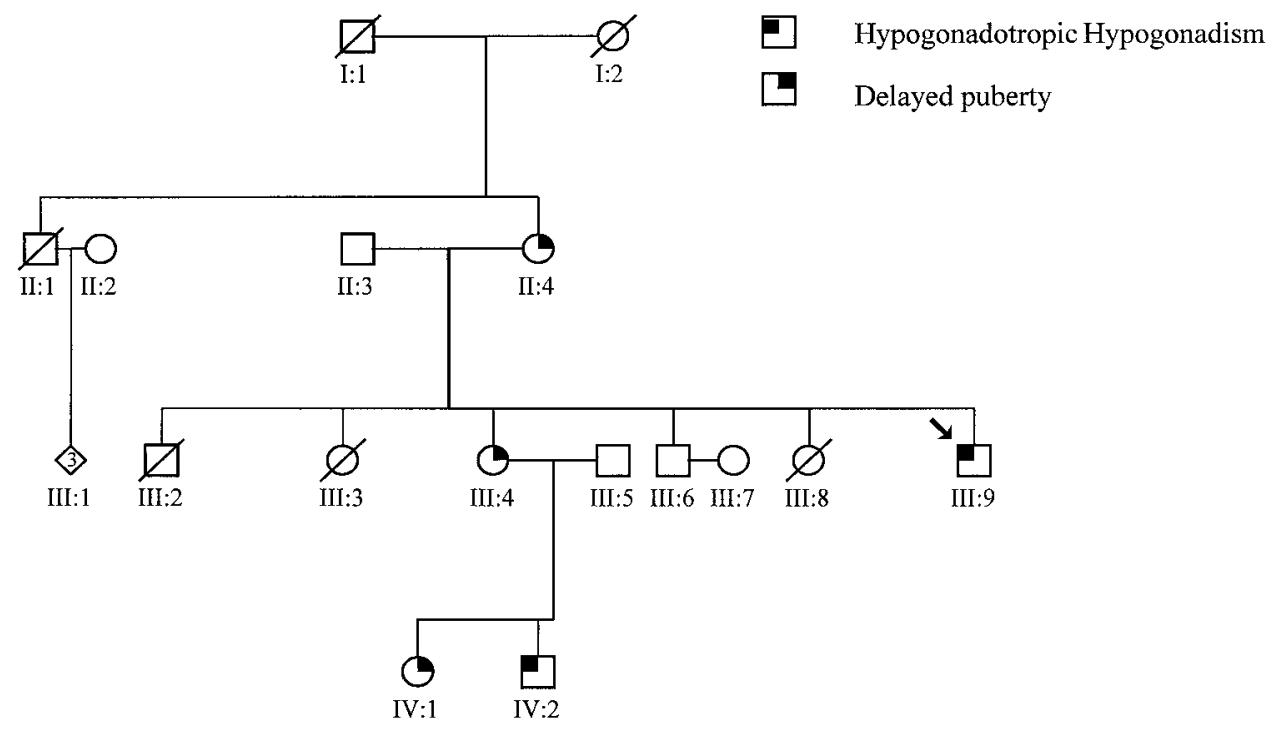



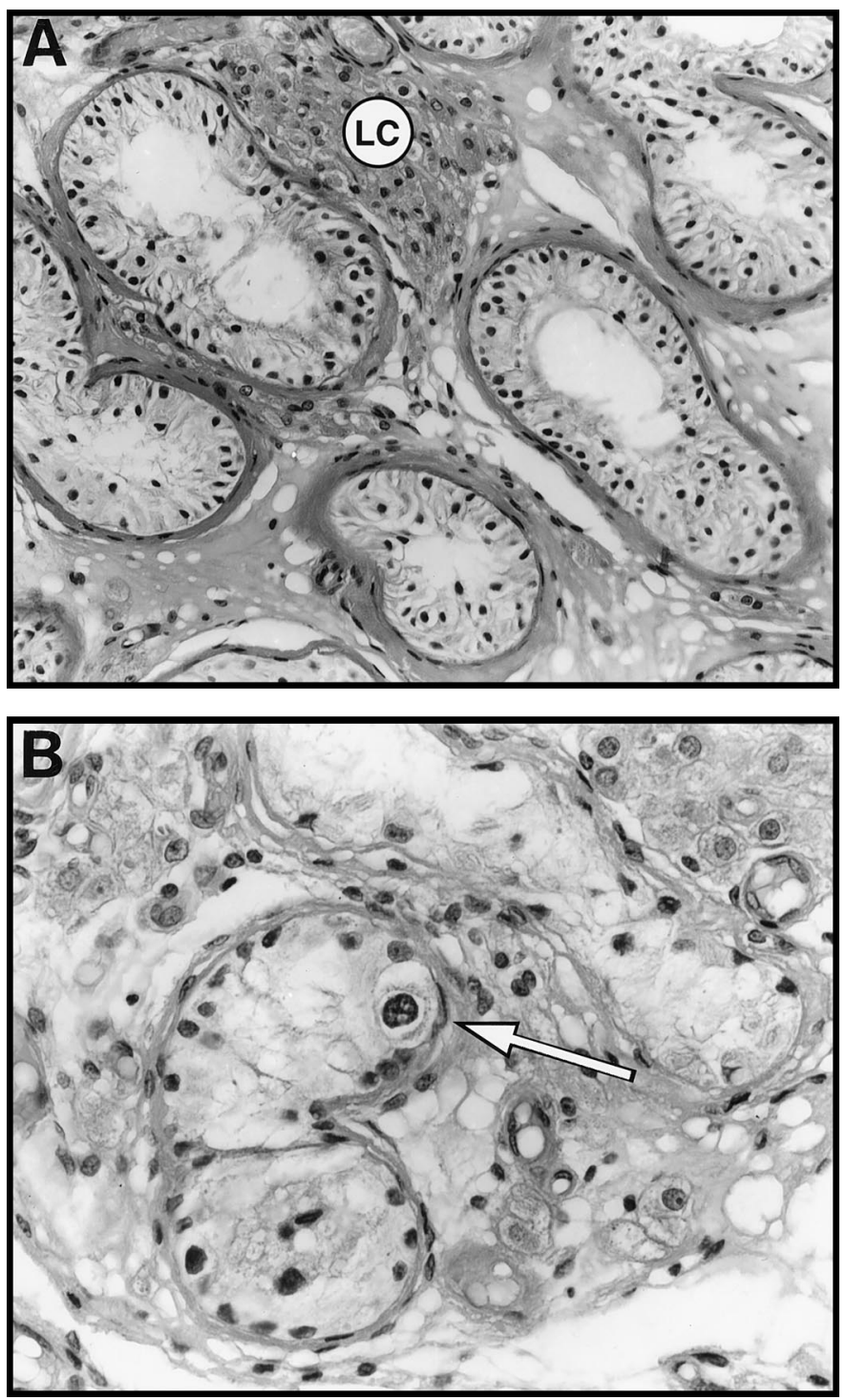

FIG. 2. Photomicrographs $(\mathrm{A}, \times 200 ; \mathrm{B}, \times 400)$ of the testicular biopsy of the proband, III-9, after 5 yr of low dose hCG therapy. A, Sertoli cell only syndrome with no germ cells demonstrable within the seminiferous tubules. LC, Leydig cell hyperplasia. B, Higher magnification of single seminiferous tubule. The arrow demarcates one of the rare spermatogonia identified in the specimen.

presenting primarily with hypoglycemia, once at 15 months during gastroenteritis and otitis media, and once at $7 \mathrm{yr}$, with gastroenteritis, vomiting, and fever. At 9 2/12 yr, IV-2 underwent dynamic anterior pituitary testing. In response to $0.10 \mathrm{U} / \mathrm{kg}$ insulin, his $\mathrm{GH}$ level rose from 14 to $33 \mathrm{ng} / \mathrm{mL}$ (normal, >10). His cortisol level showed no response, with a baseline level of $11 \mu \mathrm{g} / \mathrm{dL}$ that failed to increase during testing. In response to $400 \mu \mathrm{g}$ TRH, his TSH levels rose from a baseline of 1.3 $\mu \mathrm{IU} / \mathrm{mL}$ to a peak TSH of $5.0 \mu \mathrm{IU} / \mathrm{mL}$, an inadequate response (normal, increase of 10-30). His PRL rose from a baseline of $6 \mathrm{ng} / \mathrm{mL}$ to a peak level of $52 \mathrm{ng} / \mathrm{mL}$ (normal, $>20$ or 3 times baseline). In response to 100 $\mu \mathrm{g}$ GnRH, LH remained less than $0.5 \mu \mathrm{IU} / \mathrm{mL}$ and FSH less than 1.0 $\mu \mathrm{IU} / \mathrm{mL}$ at all time points. At a chronological age of $92 / 12 \mathrm{yr}, \mathrm{IV}-2$ 's bone age was $6 \mathrm{yr}$.

At $123 / 12 \mathrm{yr}$, patient IV-2 continued to be well below the fifth percentile on the normal growth curves (height, 51 in.; height age, 86/12 yr; predicted height using Bayley prediction tables, 68 in.). Physical examination revealed no pubic or axillary hair and prepubertal testes. Bone age remained markedly delayed at $66 / 12$ to 8 yr. On repeat GnRH stimulation testing, testosterone levels at 1 and 120 min were less than
$3 \mathrm{ng} / 100 \mathrm{mg}$. FSH levels rose from $2.4 \mu \mathrm{IU} / \mathrm{mL}$ to a peak of $4.6 \mu \mathrm{IU} / \mathrm{mL}$ at $120 \mathrm{~min}$. LH levels rose from $0.16 \mu \mathrm{IU} / \mathrm{mL}$ to a peak of $1.1 \mu \mathrm{IU} / \mathrm{mL}$ at $60 \mathrm{~min}$.

\section{Clinical studies}

After obtaining written informed consent, both patients were admitted to the General Clinical Research Center at the Massachusetts General Hospital, patient III-9 in 1980 (age 22 yr) and patient IV-2 in 1998 (age 15 yr). Patient III-9 discontinued his hCG for 8 weeks before the study, and patient IV-2 was not taking any hormone replacement therapy. Frequent blood sampling every 10-20 min was performed for 12.5-24 h for measurement of LH, FSH, and FAS. FSH levels were measured from hourly pools, and testosterone levels were measured from 6-h pools of serum. After completion of frequent sampling, each patient received pulsatile $\mathrm{GnRH}(25 \mathrm{ng} / \mathrm{kg})$ sc via pulsatile pump every $2 \mathrm{~h}$ for $6-7$ days. Each morning while using the GnRH pump, gonadotropin responses to a single iv GnRH bolus were monitored. LH, FSH, and FAS levels were determined every $15 \mathrm{~min}$ for $2 \mathrm{~h}$ after the GnRH pulse.

\section{Assays}

Serum LH and FSH concentrations were determined by immunoassays calibrated against the Second International Reference Preparation of human menopausal gonadotropin (hMG; WHO 71/223) (15-17). For patient III-9, the minimum detectable dose was $0.8 \mathrm{mIU}$ hMG (WHO $71 / 223) / \mathrm{mL}$; for patient IV-2, the minimum detectable dose was $1.6 \mathrm{mIU}$ hMG (WHO 71/223)/mL. Inter- and intraassay coefficients of variation were less than $10 \%$. FAS was measured using a monoclonal antibody RIA, with a highly purified $\alpha$-subunit of hCG as the standard $(18,19)$. Testosterone levels were also measured by RIA (20). Secretory patterns were analyzed for pulses using a modified version of the Santen and Bardin method (21). Statistical analysis was performed using a Newman-Keuls ANOVA.

\section{Direct sequencing of $D A X 1$}

After obtaining informed consent, blood samples were taken from individuals II-4, III-4, III-9, IV-1, and IV-2, and leukocyte DNA was extracted. Exons 1 and 2 of $D A X 1$ were amplified by PCR using primers and conditions described previously (5). Direct sequencing of PCR products was performed using the dRhodamine terminator cycle sequencing kit (Perkin-Elmer Corp., Palo Alto, CA) and automated sequencer (model 377, PE Applied Biosystems, Foster City, CA). After detection of a mutation, additional primers were used to PCR amplify the region of interest (forward, 5'-GCTCAAAGCAAACGCACGTGGCTC-3'; reverse, 5'-GACGAAGCGCAGCGTCTTCAACAG-3'). Restriction enzyme analysis of this DNA fragment was performed using MspI (Promega Corp., Madison, WI).

\section{Results}

\section{Mutation analysis of the DAX1 gene}

Direct sequencing of DAX1 revealed a hemizygous 501delA mutation in both the proband (III-9) and his affected nephew [IV-2; Fig. 3A; A of the ATG start codon designated +1 ; 501 delA of IV-2 previously reported (22)]. This single nucleotide deletion results in a frame shift and premature stop codon at position 263. Three women (II-4, III-4, and IV-1) from different generations of this kindred, each with markedly delayed puberty, were all heterozygous for this 501delA mutation (Fig. 3A). Deletion of this nucleotide creates a novel $M s p$ I restriction site. Restriction enzyme analysis confirmed the hemizygous status of affected males and the heterozygous carrier status of females (Fig. 3B).

\section{Baseline gonadotropin secretion}

Patient III-9 (Fig. 4A) exhibited apulsatile gonadotropin secretion, with LH levels below the limits of detection of the 


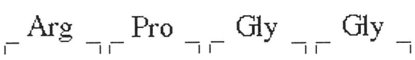

$C \mathrm{GGCCAGGGGGC}$

Wild

Type
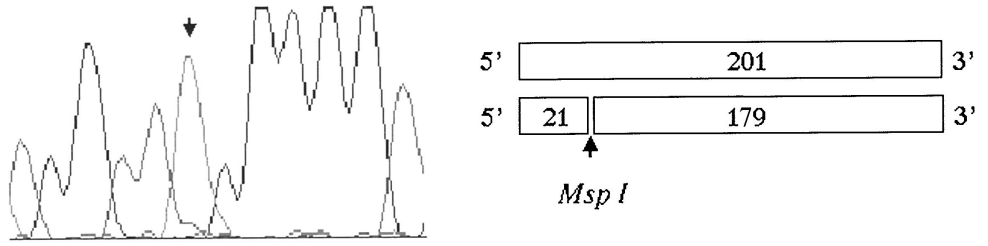

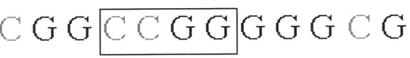

Hemizygous

Male

(III:9, IV:2)

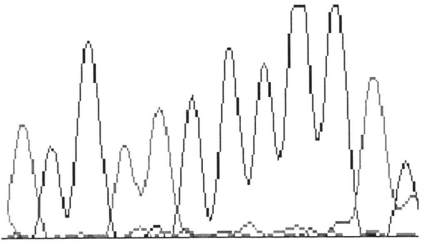

WT II:4 III:4 IV:1 III:9 IV:2

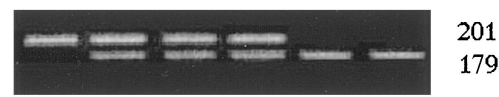

\section{Heterozygous \\ Female}

(II:4, III:4, IV:1)
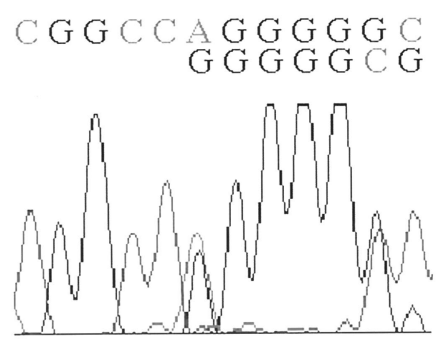

FIG. 3. Left, Direct DNA sequencing revealed a hemizygous 501delA mutation in affected males (III-9 and IV-2). Females (II-4, III-4, and IV-1) appeared heterozygous for this mutation. Right, Deletion of this nucleotide creates a novel $M s p$ I restriction site (C/CGG) in the sequence. Carrier status could therefore be confirmed by restriction analysis.

assay $(<0.8 \mathrm{mIU} / \mathrm{mL})$. FSH levels were at the low end of the normal male range (mean FSH, $1.2 \mathrm{mIU} / \mathrm{mL}$ ), but FAS levels were well within the normal range (mean FAS, $126.2 \mathrm{pg} /$ $\mathrm{mL})$. Six FAS pulses were detected by modified Santen and Bardin analysis. In patient IV-2 (Fig. 4B), LH levels were below the limits of detection $(<1.6 \mathrm{mIU} / \mathrm{mL})$ for every data point in the study. Mean FSH and FAS levels equaled 3.5 $\mathrm{mIU} / \mathrm{mL}$ and $34.9 \mathrm{pg} / \mathrm{mL}$, respectively. No FAS pulses were detectable.

\section{Response to pulsatile GnRH}

Both III-9 and IV-2 received pulsatile GnRH for 7 and 6 days, respectively, to examine their pituitary responsiveness to exogenous pulsatile GnRH (Fig. 5). There was no initial gonadotropin pulse for either patient on day 1 of therapy. For patient III-9, FSH levels tripled from day 1 to day 7 of GnRH therapy $(P<0.001$; Fig. 5A). LH levels remained at the level of assay sensitivity for the first 4 days of the study, then increased significantly over the course of the last 3 days $(P<0.005)$. Testosterone levels increased from 6 to $141 \mathrm{ng} / \mathrm{dL}$ during the week. FAS levels did not change significantly.

Patient IV-2 demonstrated no change in LH, FAS, or testosterone levels over the course of 6 days of GnRH therapy (Fig. 5B). However, mean FSH levels increased modestly, but significantly, from day 1 to day $6(P<0.001)$.

\section{Discussion}

This study examines genotype/phenotype correlations in both the male and female members of an extended kindred with congenital adrenal hypoplasia. Despite extensive therapy with exogenous gonadotropins, the proband of this kindred, III-9, was not able to achieve fertility. The family history coupled with the mutation analysis strongly suggest that delayed puberty may be a manifestation of X-linked $D A X 1$ gene defects in female heterozygotes. Both the proband and his nephew demonstrated minimal responses to exogenous pulsatile GnRH. However, the proband demonstrated an erratic pattern of FAS secretion at baseline, as has been previously documented in patients with $\mathrm{AHC} / \mathrm{HH}(14)$, whereas his nephew had no evidence of endogenous gonadotropin secretion. These observations raise a number of new issues about AHC, including 1) the variety of phenotypes included within the diagnosis, and 2) the spectrum of presentations within a family.

In the rat, Dax-1 is expressed in Sertoli cells, with maximal levels present during the first spermatogenic wave (postnatal days 20 and 30) (23). However, Dax-1 expression declines to low basal levels in the 40-day-old, sexually mature animal, demonstrating a pattern of developmental regulation. The mouse model of AHC, created by targeted disruption of the mouse homolog of DAX1 (Ahch), has extended our understanding of the role of this gene mutant in gonadal function 
A
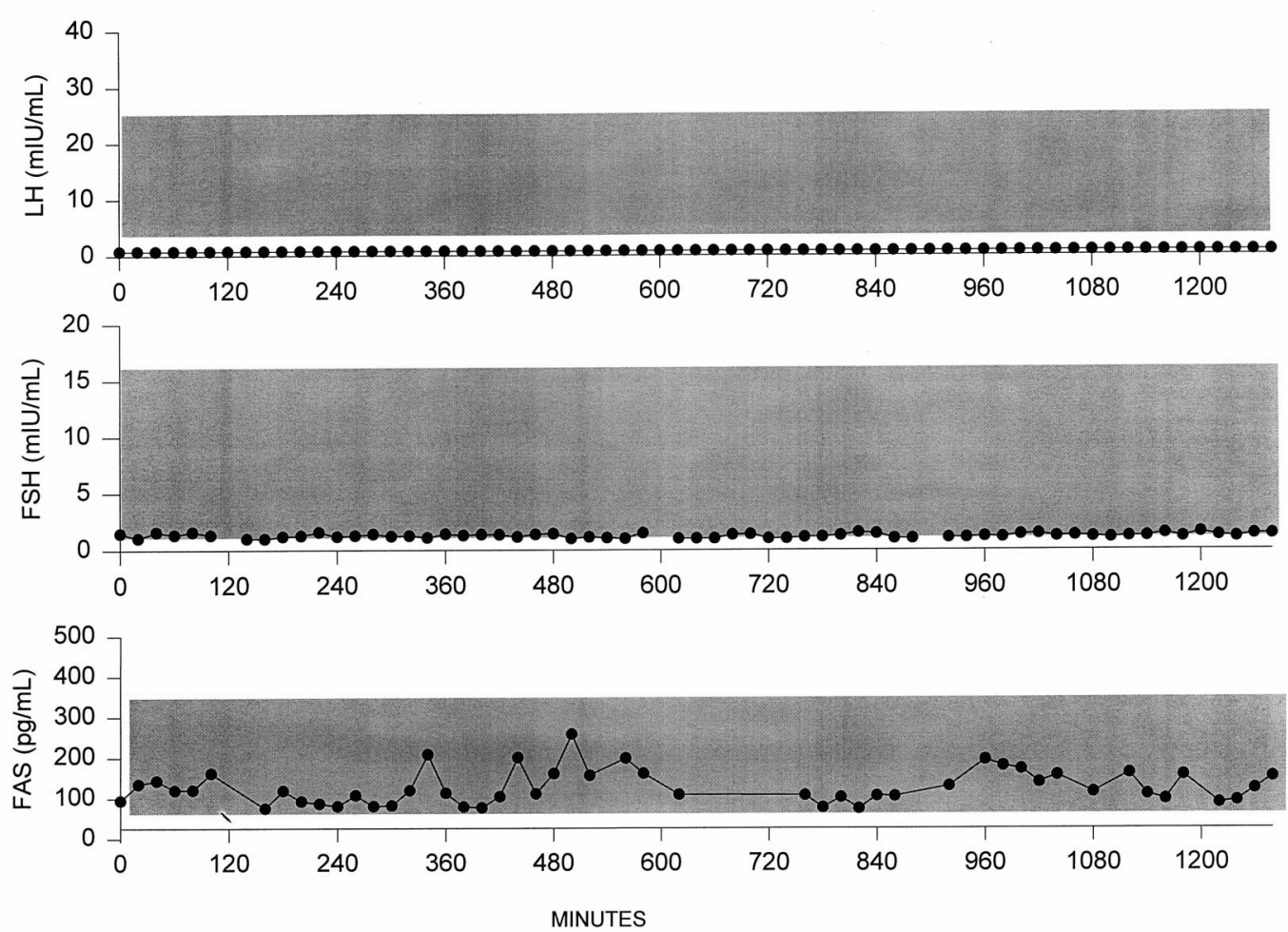

B
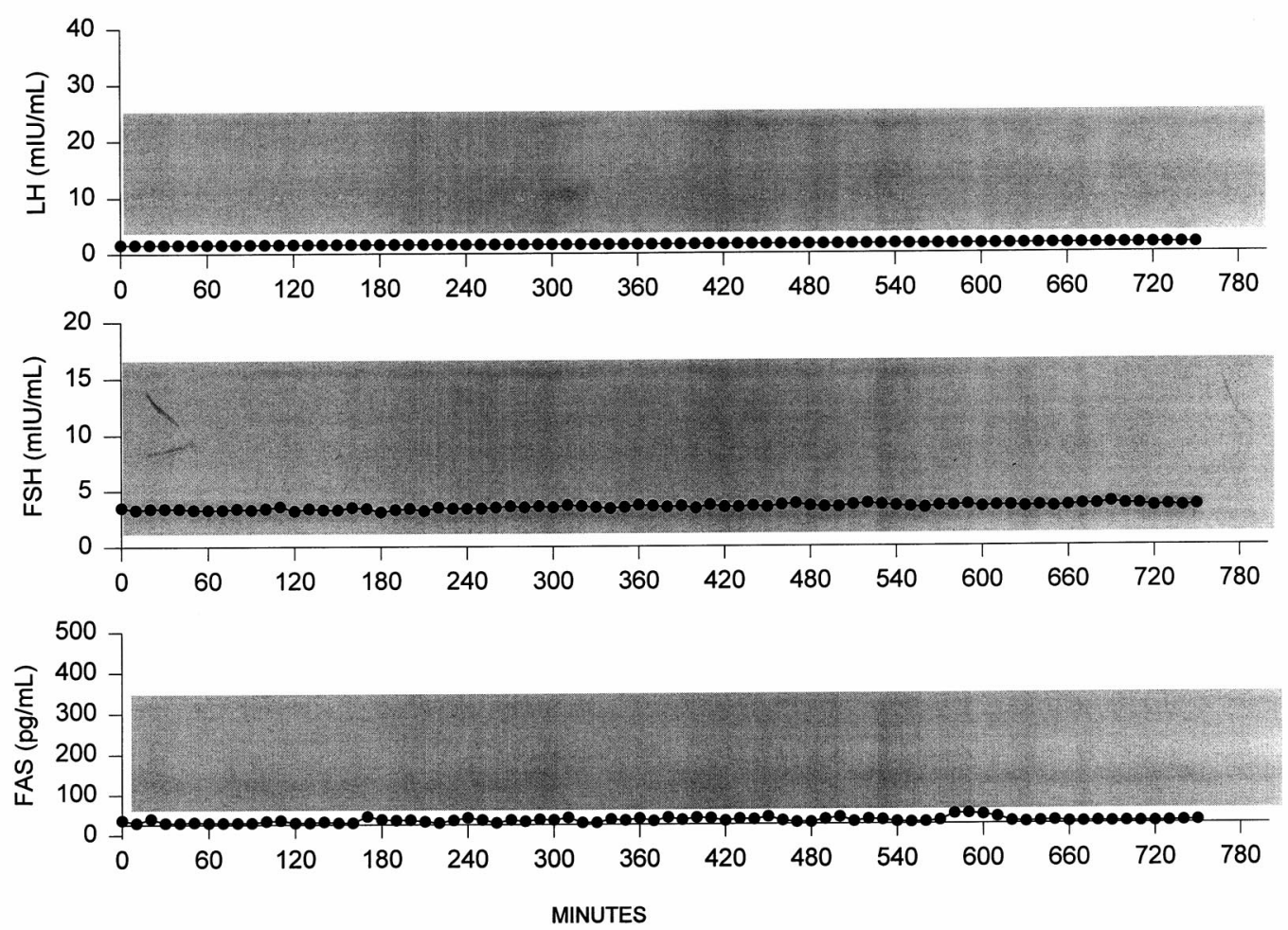

FIG. 4. Baseline secretory pattern of LH and FAS in III-9 (A) and IV-2 (B). Each graph depicts the results of gonadotropin determinations made at 10- to 20-min intervals. Patient III-9 was studied for $24 \mathrm{~h}$; patient IV-2 was studied for $12.5 \mathrm{~h}$. The shaded area for LH and FSH represents the mean \pm 2 SD for each hormone as determined in 20 normal men. 
A
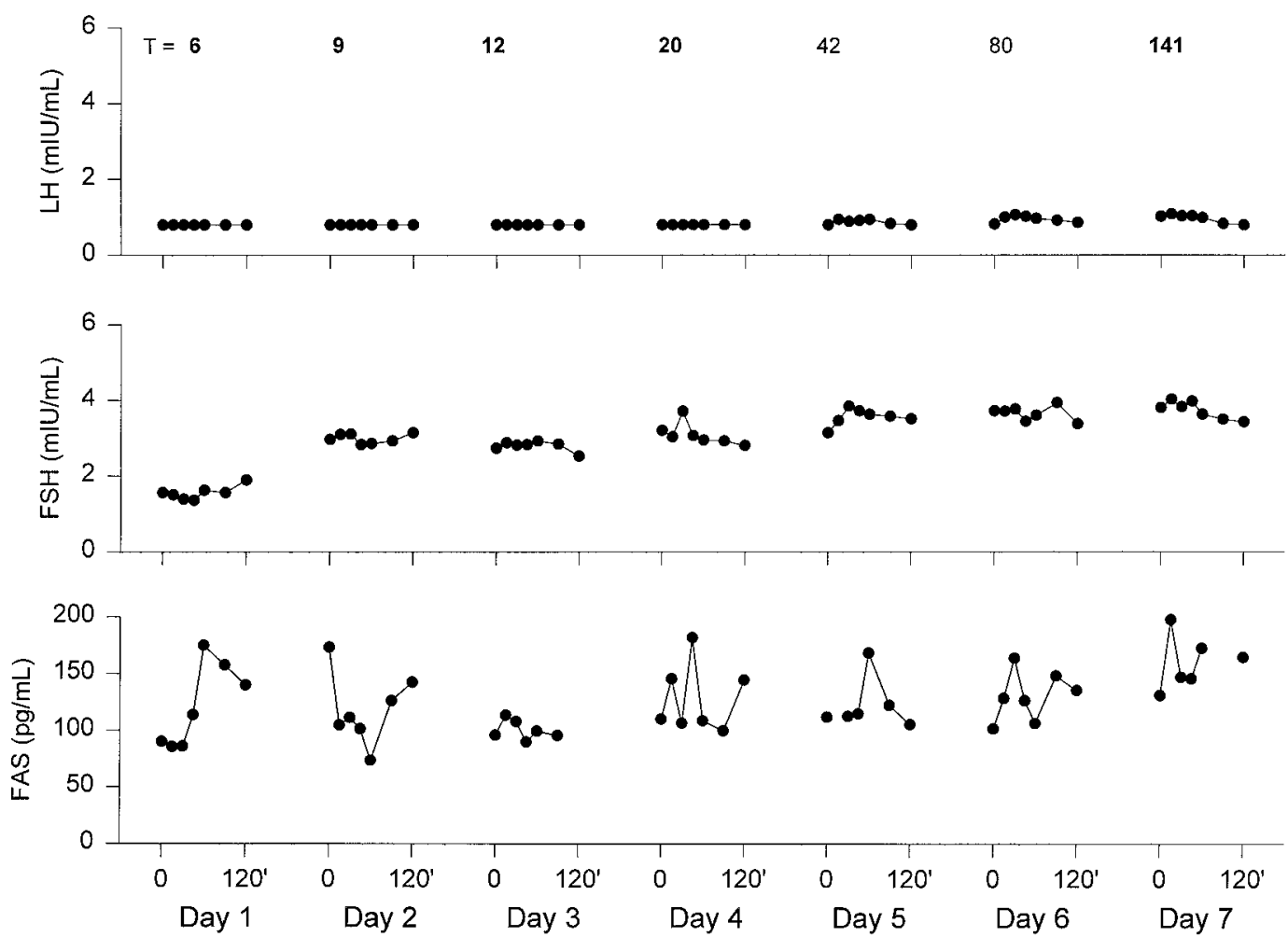

B
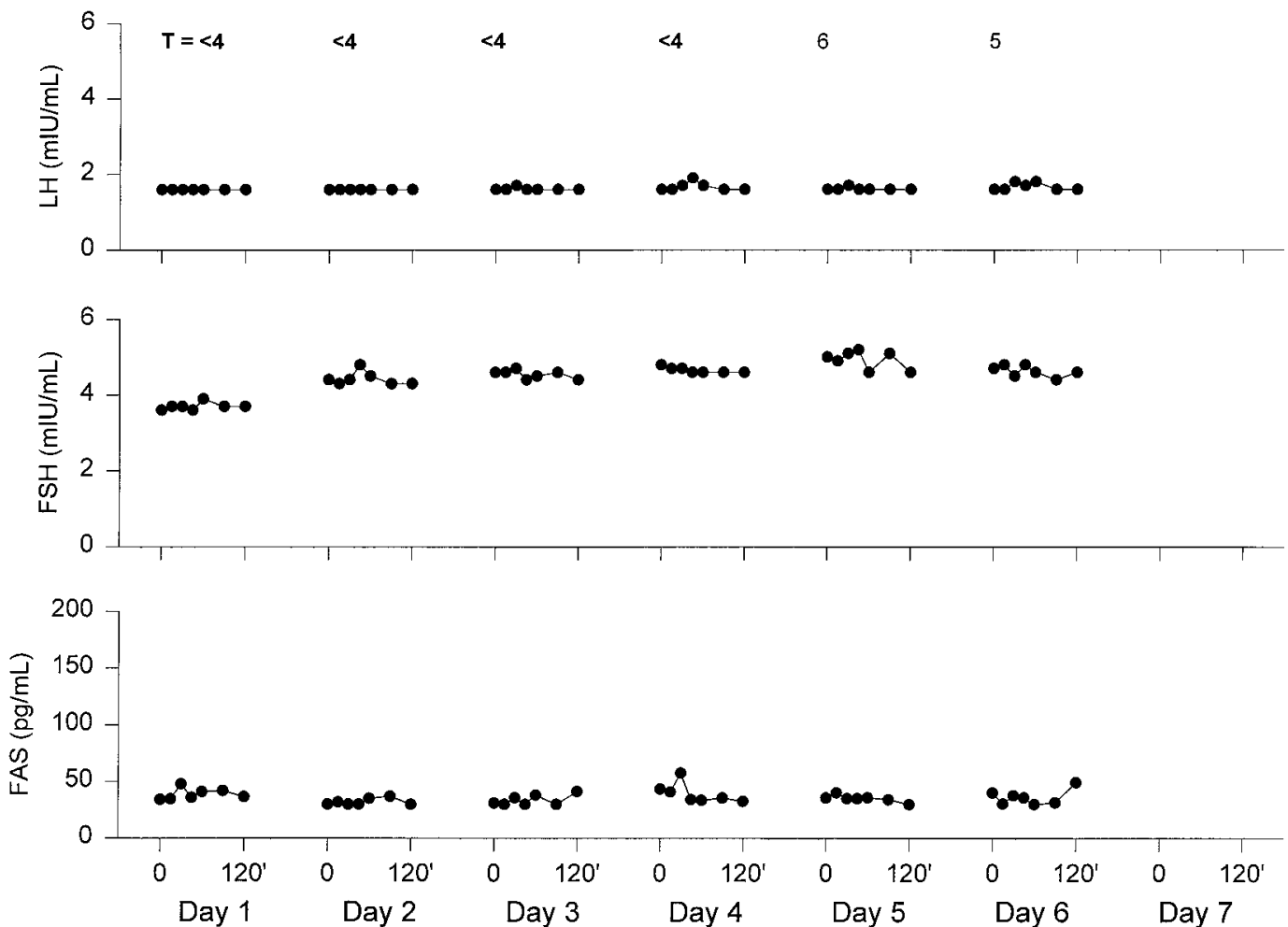

FIG. 5. Gonadotropin responses to 6-7 days of pulsatile GnRH in III-9 (A) and IV-2 (B). Each patient received pulsatile GnRH (25 ng/kg, iv, every $2 \mathrm{~h}$ ). A single GnRH pulse was monitored each morning. Testosterone levels are indicated at the top of each panel. Note the change in axes compared with Fig. 4. Refer to Fig. 4 for normative ranges. 
(7). Based on observations in the human, it was originally hypothesized that the hypogonadism of AHC in mice would be due to deficient gonadotropin secretion. However, mutant mice had normal levels of LH and FSH; pituitary immunohistochemical staining for $\mathrm{LH} \beta$ and $\mathrm{FSH} \beta$ was also normal. Male mice demonstrated a primary testicular defect with progressive seminiferous tubule epithelial degeneration, leading to a complete loss of germ cells by 14 weeks. Leydig cell hyperplasia was also observed, suggesting either an independent Leydig cell defect due to Ahch disruption or a secondary response to the Sertoli cell defect.

Although the differences between human and mouse phenotypes could be explained by species-specific pathways, there is a paucity of data regarding testicular histology and induction of spermatogenesis in men with AHC. Schwartz et al. reported the case of an affected male who underwent a short course of pulsatile GnRH and produced a semen sample with a few spermatozoa (24). However, further details regarding sperm count, morphology, and motility were not described. In the present report, the proband underwent a testicular biopsy after $7 \mathrm{yr}$ of low dose hCG therapy, revealing essentially Sertoli cell only syndrome with Leydig cell hyperplasia. However, 3 yr of escalating doses of both hCG and Pergonal failed to induce spermatogenesis despite an increase in testicular size from 5 to $10 \mathrm{cc}$. These findings suggest that even when bypassing the hypothalamic-pituitary axis with exogenous gonadotropins, AHC patients can harbor an intrinsic gonadal defect. The degeneration of large segments of the seminiferous tubules observed in knockout mice suggests that Ahch is necessary for maintenance of epithelial integrity and spermatogenesis. Extending this concept to the human male, restoration of a normal hormonal milieu in $\mathrm{AHC} / \mathrm{HH}$ appears unable to overcome this defect.

The age of onset of AHC appears to be variable. Most patients present with salt wasting in neonatal life, but a significant fraction are well into their childhood years before presentation (5). Although the hypogonadotropic hypogonadism associated with AHC is conventionally perceived as a congenital disorder, recent data have demonstrated transient postnatal activation of the HPG axis in AHC patients. Normal serum gonadotropin and testosterone levels have been demonstrated in a newborn male with $\mathrm{AHC}$ and a confirmed DAX1 mutation (A300V) (25). Hormonal data from four boys with AHC (aged 1-3 months) have also suggested an active HPG axis (26). In the current report, the proband's nephew demonstrated a neonatal testosterone level of $209 \mathrm{ng} / \mathrm{dL}$ in the setting of a LH level of $6 \mathrm{mIU} / \mathrm{mL}$ during this same developmental window. These findings suggest that the mechanisms that control neonatal activation of the HPG axis may be distinct from those occurring at puberty or that the hypogonadotropic hypogonadism of AHC worsens over time. Therefore, our understanding of the hypogonadotropic hypogonadism associated with AHC continues to evolve, encompassing defects at the hypothalamus, pituitary, and perhaps even gonad, with congenital and developmental components.

Despite these insights into the age spectrum of AHC in male patients, until recently, little information has been available regarding the adrenal or pubertal phenotype in female carriers of DAX1 gene mutations. Merke et al. reported two boys with $\mathrm{AHC} / \mathrm{HH}$ and a nonsense mutation in the DNAbinding domain of the DAX1 gene (8). The boys' maternal aunt, who was homozygous for the nonsense mutation through gene conversion, had the phenotype of isolated hypogonadotropic hypogonadism, demonstrating a surprising range of phenotypes in this one family. In the kindred reported here, three female heterozygotes carrying the del501A mutation all underwent markedly delayed menarche. Delayed puberty in female carriers may thus represent a forme fruste of the hypogonadotropic hypogonadism associated with AHC. Although it is possible that there are other etiologies for the delayed puberty in these women, no commonly implicated physiological or genetic factors could be elicited by history. Although the women in this kindred may have had an incomplete form of central hypogonadism, there is no evidence to suggest that any of them had adrenal dysfunction. The possibility that these women might have had abnormal DHEAS or aldosterone levels or diminished adrenal reserve on formal ACTH testing could not be studied.

Partial expression of X-linked disorders in heterozygous females has been well documented for a number of conditions, including ornithine transcarbamylase deficiency (27, $28)$, Duchenne muscular dystrophy $(29,30)$, and fragile $X$ mental retardation (31). Although it is assumed that female somatic cells undergo a 50:50 random $X$ inactivation, this is often not true in a given individual or clonal cell population. Therefore, if a female carrier has a higher proportion of mutant alleles on the active X-chromosome in a relevant cell lineage (i.e. skewing), she may show symptoms similar to those of a hemizygous affected male, as has been observed in hemophilia B (32). Although in the current report, multiple females within a single kindred had delayed menarche, familial nonrandom $X$ inactivation has been described in some rare pedigrees [Duchenne muscular dystrophy (30) and hemophilia B (33)]. Although no direct evidence is presented in the current study to support familial skewing, the possibility of genetic determinants in the randomness of $X$ inactivation remains an important model to consider $(34,35)$. In addition to extended pedigrees, further studies will be needed to determine whether DAX1 mutations occur in females with delayed puberty who do not have a family history of $\mathrm{AHC} / \mathrm{HH}$.

Long term data on hypothalamic-pituitary-gonadal function in patients with $\mathrm{AHC} / \mathrm{HH}$ are also lacking. Age at diagnosis has been used to assess the severity of AHC (5), but no standardized biochemical testing yet appears available as a marker of reproductive phenotype. Using pulsatile GnRH therapy, investigators have observed patterns consistent with both hypothalamic and pituitary defects $(9-14)$. In the current study, both the proband and his nephew shared many similarities with respect to their gonadotropin profiles. Neither individual demonstrated LH pulsatility at baseline. During a 1-week exposure to exogenous pulsatile GnRH, both patients demonstrated significant elevations of FSH compared to baseline levels, but the responses were very modest compared to those in patients with Kallmann syndrome, a type of $\mathrm{HH}$ due to an isolated hypothalamic defect in GnRH secretion. Our group has shown that Kallmann's patients given an identical regimen of pulsatile GnRH dem- 
onstrate a more robust gonadotropin response, with marked increases in both LH and FSH secretion occurring within 1 week (14).

Despite these gross similarities, there were also some important differences in the gonadotropin profiles between the affected males of this kindred. Although IV-2 had flat FAS levels, III-9 had FAS levels well within the normal male range with evidence of erratic pulsatility, suggesting GnRH-independent stimulation to the gonadotrope. Patient III-9 also had significant elevations of both LH and FSH over the week of GnRH exposure, whereas IV-2 demonstrated a significant change in only FSH. Patient III-9's rise in LH, although quite subtle, was accompanied by a marked rise in his testosterone level from $6 \mathrm{ng} / \mathrm{dL}$ (day 1) to $141 \mathrm{ng} / \mathrm{dL}$ (day 7). Prior therapy with hCG may have allowed III-9 to achieve a greater mass of Leydig cells and hence an increase in testosterone compared to his nephew, although both received identical pulsatile GnRH regimens and had similarly meager LH responses. Nonetheless, one might have expected a somewhat more dramatic rise in LH to have accompanied the elevation in testosterone, raising the possibility that FSH itself may induce Leydig cell steroidogenesis or that it stimulates another factor to induce testosterone production. Although recombinant FSH does not appear to have a direct effect on testosterone production in vitro, recent data suggest that FSH may increase the production of a Sertoli cell-secreted factor able to up-regulate testicular steroidogenesis (36). Therefore, although both patients demonstrated atypical responses to GnRH compared to other states of GnRH deficiency, subtle differences between these two patients suggest that the proband has a less severe reproductive phenotype than his nephew.

In addition, the proband of this family survived $12 \mathrm{yr}$ without glucocorticoid or mineralocorticoid replacement, suggesting that he also has a less severe form of adrenal insufficiency. Intrafamilial variability in the temporal expression and degree of adrenal insufficiency has been reported by a number of investigators (5). In a kindred previously reported by our group, the presentation of adrenal insufficiency spanned 1 day to 8 yr among affected individuals (14). The proband's nephew never had steroid therapy withdrawn after neonatal life, so it is not known whether he could have survived off of therapy. In the future, serial monitoring of ACTH levels in male patients with known DAX1inactivating mutations may help investigators to more precisely determine the onset of adrenal insufficiency. Although most AHC patients are found to have $\mathrm{HH}$ when they reach pubertal age, not all patients have been found to have mutations in the DAX1 gene, suggesting that other gene defects or epigenetic phenomena may lead to the same phenotype (3).

In summary, this study adds to the growing body of information of the hypogonadism of AHC and expands the phenotype of this disorder to include intrinsic defects in spermatogenesis in men and possibly delayed puberty in women. Both members of this kindred demonstrated gonadotropin profiles consistent with a pituitary defect, but subtle differences between the profiles suggest that the reproductive phenotype was less severe in the proband.

\section{References}

1. Kerenyi N. 1961 Congenital adrenal hypoplasia. Report of a case with extreme adrenal hypoplasia and neurohypophyseal aplasia, drawing attention to certain aspects of etiology and classification. Arch Pathol. 71:114-121.

2. Golden MP, Lippe B, Kaplan SA. 1977 Congenital adrenal hypoplasia and hypogonadotropic hypogonadism. Am J Dis Child. 131:1117-1118.

3. Muscatelli F, Strom TM, Walker AP, et al. 1994 Mutations in the DAX-1 gene give rise to both $\mathrm{X}$-linked adrenal hypoplasia congenita and hypogonadotropic hypogonadism. Nature. 372:672-676.

4. Zanaria E, Muscatelli F, Bardoni B, et al. 1994 An unusual member of the nuclear hormone receptor superfamily responsible for X-linked adrenal hypoplasia congenita. Nature. 372:635-641.

5. Reutens AT, Achermann JC, Ito M, et al. 1999 Clinical and functional effects of mutations in the DAX-1 gene in patients with adrenal hypoplasia congenita. J Clin Endocrinol Metab. 84:504-511.

6. Ito M, Yu R, Jameson JL. 1997 DAX-1 inhibits SF-1 mediated transactivation via a carboxy-terminal domain that is deleted in adrenal hypoplasia congenita. Mol Cell Biol. 17:1476-1483.

7. Yu RN, Ito M, Saunders TL, Camper SA, Jameson JL. 1998 Role of Ahch in gonadal development and gametogenesis. Nat Genet. 20:353-357.

8. Merke DP, Tajima T, Baron J, Cutler Jr GB. 1999 Hypogonadotropic hypogonadism in a female caused by an X-linked recessive mutation in the DAX1 gene. N Engl J Med. 340:1248-1252.

9. Kruse K, Sippell WG, Schnakenburg KV. 1984 Hypogonadism in congenital adrenal hypoplasia: evidence for a hypothalamic origin. J Clin Endocrinol Metab. 58:12-17.

10. Gordon D, Cohen HN, Beastall GH, Hay ID, Thomson JA. 1984 Contrasting effects of subcutaneous pulsatile GnRH therapy in congenital adrenal hypoplasia and Kallmann's syndrome. Clin Endocrinol (Oxf). 21:597-603.

11. Kikuchi K, Kaji M, Momoi T, Mikawa H, Shigematsu Y, Sudo M. 1987 Failure to induce puberty in a man with X-linked congenital adrenal hypoplasia and hypogonadotropic hypogonadism by pulsatile administration of low-dose gonadotropin-releasing hormone. Acta Endocrinol (Copenh). 114:153-160.

12. Bovet P, Reymond MJ, Rey F, Gomez F. 1988 Lack of gonadotropic response to pulsatile gonadotropin-releasing hormone in isolated hypogonadotropic hypogonadism associated to congenital adrenal hypoplasia. J Endocrinol Invest. 11:201-204.

13. Partsch CJ, Sippell WG. 1989 Hypothalamic hypogonadism in congenital adrenal hypoplasia. Horm Metab Res. 21:623-625.

14. Habiby RL, Boepple P, Nachtigall L, Sluss PM, Crowley Jr WF, Jameson JL. 1996 Adrenal hypoplasia congenita with hypogonadotropic hypogonadism. Evidence that DAX-1 mutations lead to combined hypothalamic and pituitary defects in gonadotropin production. J Clin Invest. 98:1055-1062.

15. Crowley Jr WF, Beitins IZ, Vale W, et al. 1980 The biologic activity of a potent analogue of gonadotropin-releasing hormone in normal and hypogonadotropic men. N Engl J Med. 302:1052-1057.

16. Filicori M, Butler JP, Crowley Jr WF. 1984 Neuroendocrine regulation of the corpus luteum in the human. Evidence for pulsatile progesterone secretion. J Clin Invest. 73:1638-1647.

17. Welt CK, Adams JM, Sluss PM, Hall JE. 1999 Inhibin A and inhibin B response to gonadotropin withdrawal depends on stage of follicle development. J Clin Endocrinol Metab. 84:2163-2169.

18. Whitcomb RW, Sangha JS, Schneyer AL, Crowley Jr WF. 1989 Improved measurement of free alpha subunit of glycoprotein hormones by assay with use of a monoclonal antibody. Clin Chem. 34:2022-2025.

19. Whitcomb RW, O'Dea LStL, Finkelstein JS, Heavern DM, Crowley Jr WF. 1990 Utility of free $\alpha$-subunit as an alternative neuroendocrine marker of gonadotropin-releasing hormone $(\mathrm{GnRH})$ stimulation of the gonadotroph in the human: evidence from normal and GnRH-deficient men. J Clin Endocrinol Metab. 70:1654-1661.

20. Rao PN, Moore PH. 1976 Synthesis of new steroid haptens for radioimmunoassay. I. 15 $\alpha$-Carboxymethylmercaptotestosterone-bovine serum albumin conjugate: measurement of testsoterone in male plasma without chromatography. Steroids. 28:101-109.

21. Santen RJ, Bardin CW. 1973 Episodic luteinizing hormone secretion in man. Pulse analysis, clinical interpretation, physiologic mechanisms. J Clin Invest. 52:2617-2628.

22. Zhang Y-H, Guo W, Wagner RL, et al. 1998 DAX1 mutations map to putative structural domains in a deduced three-dimensional model. Am J Hum Genet. 62:855-864

23. Tamai KT, Monaco L, Alastalo TP, Lalli E, Parvinen M, Sassone-Corsi P. 1996 Hormonal and developmental regulation of DAX-1 expression in Sertoli cells. Mol Endocrinol. 10:1561-1569.

24. Schwartz M, Blichfeldt S, Muller J. 1997 X-linked adrenal hypoplasia in a large Greenlandic family. Detection of a missense mutation (N440I) in the DAX-1 gene; implication for genetic counseling and carrier diagnosis. Hum Genet. 99:83-87.

25. Takahashi T, Shoji Y, Haraguchi N, Takahashi I, Takada G. 1997 Active hypothalamic-pituitary-gonadal axis in an infant with $\mathrm{X}$-linked adrenal hypoplasia congenita. J Pediatr. 130:485-488. 
26. Peter M, Matthias V, Partsch C-J, Sippell WG. 1998 Congenital adrenal hypoplasia: clinical spectrum, experience with hormonal diagnosis, and report on new point mutations of the DAX-1 gene. J Clin Endocrinol Metab. 83:2666-2674.

27. Rowe PC, Newman SL, Brusilow SW. 1986 Natural history of symptomatic partial ornithine transcarbamylase deficiency. N Engl J Med. 314:541-547.

28. Batshaw ML, Msall M, Beaudet AL, Trojak J. 1986 Risk of serious illness in heterozygotes for ornithine transcarbamylase deficiency. J Pediatr. 108:236-241.

29. Moser H, Emery AE. 1974 The manifesting carrier in Duchenne muscular dystrophy. Clin Genet. 5:271-284.

30. Kaladhar Reddy B, Anandavalli TE, Reddi OS. 1984 X-linked Duchenne muscular dystrophy in an unusual family with manifesting carriers. Hum Genet. 67:460-462.

31. Rousseau F, Heitz D, Oberle I, Mandel JL. 1991 Selection in blood cells from female carriers of the fragile $X$ syndrome: inverse correlation between age and proportion of active X chromosomes carrying the full mutation. J Med Genet. 28:830-836.

32. Kling S, Coffey AJ, Ljung R, et al. 1991 Moderate haemophilia B in a female carrier caused by preferential inactivation of the paternal X chromosome. Eur J Haematol. 47:257-261.

33. Taylor SA, Deugau KV, Lillicrap DP. 1991 Somatic mosaicism and femaleto-female transmission in a kindred with hemophilia B (factor IX deficiency). Proc Natl Acad Sci USA. 88:39-42.

34. Parolini O, Ressmann G, Haas OA, et al. 1998 X-linked Wiskott-Aldrich syndrome in a girl. N Engl J Med. 338:291-295.

35. Puck JM, Willard HF. 1998 X inactivation in females with X-linked disease. N Engl J Med. 338:325-328.

36. Levalle O, Zylbersztein C, Aszpis S, et al. 1998 Recombinant human folliclestimulating hormone administration increases testosterone production in men, possibly by a Sertoli cell-secreted nonsteroid factor. J Clin Endocrinol Metab. 83:3973-3976. 